Article

\title{
News Values on Instagram: A Comparative Study of International News
}

\author{
Ahmed Al-Rawi ${ }^{1, *(\mathbb{D}}$, Alaa Al-Musalli ${ }^{2}$ and Abdelrahman Fakida ${ }^{1}$ (D) \\ 1 School of Communication, Simon Fraser University, 8888 University Dr W K9671, \\ Burnaby, BC V5A 1S6, Canada; abdelrahman_fakida@sfu.ca \\ 2 Faculty of Business and Professional Studies, School of Communication, Capilano University, \\ 2055 Purcell Way, North Vancouver, BC V7J 3H5, Canada; alaaalmusalli@capilanou.ca \\ * Correspondence: aalrawi@sfu.ca
}

Citation: Al-Rawi, Ahmed, Alaa Al-Musalli, and Abdelrahman Fakida. 2021. News Values on Instagram: A Comparative Study of International News. Journalism and Media 2: 305-320. https://doi.org/10.3390/ journalmedia2020018

Academic Editor: Andreu

Casero-Ripollés

Received: 28 May 2021

Accepted: 9 June 2021

Published: 17 June 2021

Publisher's Note: MDPI stays neutral with regard to jurisdictional claims in published maps and institutional affiliations.

Copyright: (c) 2021 by the authors. Licensee MDPI, Basel, Switzerland. This article is an open access article distributed under the terms and conditions of the Creative Commons Attribution (CC BY) license (https:// creativecommons.org/licenses/by/ $4.0 /)$.

\begin{abstract}
This study employs the news values theory and method in the examination of a large dataset of international news retrieved from Instagram. News values theory itself is subjected to critical examination, highlighting its strengths and weaknesses. Using a mixed method that includes content analysis and topic modeling, the study investigates the major news topics most 'liked' by Instagram audiences and compares them with the topics most reported on by news organizations. The findings suggest that Instagram audiences prefer to consume general news, human-interest stories and other stories that are mainly positive in nature, unlike news on politics and other topics on which traditional news organizations tend to focus. Finally, the paper addresses the implications of the above findings.
\end{abstract}

Keywords: news values theory; Instagram news; social media; international news

\section{Introduction}

In this study, we use mixed methods to apply news values theory to examine audiences' choices of news stories, comparing these preferences to the dominant news topics that are highlighted by different international news organizations. To determine which news topics audiences prefer, we extracted the top 50 most 'liked' stories from each news outlet and manually coded the 600 news stories. Chosen for their popularity, the news channels included in this study are CNN, BBC, France 24, SkyNews, Al Jazeera, and EuroNews in both English targeting global audiences and in Arabic mostly targeting the Arab audiences. For the purpose of making general comparisons with news organizations' dominant news topics, we employed a topic modeling approach in the examination of a total of 123,683 Instagram news stories. Unlike other social media platforms, such as Twitter and Facebook, there are not many empirical studies examining news on Instagram. This could be due to the technical difficulty of scraping data from this platform, and/or a consequence of the nature of Instagram and the fact that it is still primarily viewed as a venue for entertainment, mostly targeting young people. In this study, we conduct an extensive examination of news on Instagram in order to fill a major gap in the literature using news values theory and method. As far as we are aware, this is the first large-scale study of Instagram news stories using a cross-national, comparative approach and a mixed method.

The majority of the news channels examined here are originally English language outlets that expanded by adding Arabic language service, especially following the 9/11 terrorist attacks. Since then, dozens of state-run satellite channels started airing in Arabic (Lahlali 2011), including TRT Arabic (Turkey), DW (Germany), Al-Hurra TV (USA) and RT Arabic (Russia). Many of these channels, such as BBC Arabic, have gained credibility among Arab audiences mainly due to their objective reporting and the venues they have provided for Arab audiences to interact and provide feedback (Alshaer and Hill 2010). 
Before delving into our study's results, we first provide a survey of Instagram news research followed by a theoretical framework on news values theory.

\section{Instagram News Research}

As mentioned, there are few studies that have investigated news on Instagram. A survey of the available studies will help provide an understanding of the status of research into news on Instagram. The majority of studies done thus far have focused on user-engagement on Instagram such as surveying social media users, while a smaller number of studies have offered textual and visual content analysis of Instagram news. Also, there are just a few studies on Instagram news, such as Eddy Borges-Rey (2015); Greer and Ferguson (2017); and Holiday et al. (2019), that made references to news values theory, while Al Nashmi (2018) employed the element of newsworthiness in his qualitative study.

In terms of user-engagement, Larsson (2018) conducted a comparative analysis of the four most popular news media outlets on Facebook and Instagram in Norway. The objective is twofold: to examine how these news media organizations use their corresponding social media platforms and to explore how social media users interact with the Facebook and Instagram webpages of these news media outlets. Although content analysis was not done on the news stories, the results revealed that Facebook is the preferred platform on which news organizations share information. The study also concluded that social media users tend to prefer "'lighter' or less-demanding modes of interaction with online news content", which became evident from the analysis of the news organizations' Instagram pages (Larsson 2018, p. 2225).

A few other studies of Instagram news have also focused on social media userengagement. Van Van Cauwenberge and Broersma's (2017) research, for instance, examined how Instagram and other social media platforms were used for online political participation. The study used data gathered from a 2015 web-based survey in The Netherlands in which a total of 1017 responses were analyzed. The study concluded that the use of Twitter, Instagram and YouTube news positively correlated with political participation, with Twitter and Instagram showing the strongest relationships to political engagement. The study also found that Facebook and WhatsApp use did not strongly correlate with political participation (Van Cauwenberge and Broersma 2017, p. 18).

A study by Nee (2019) looked at how teens and young adults from different countries use social media to verify news and information. The study was based on two web-based surveys, one in the Middle East conducted in October 2017 with 258 respondents, and one in the U.S. during March-May 2018 which had 643 respondents. The study also conducted focus groups with 17 young adults from 14 different home countries (Nee 2019, p. 175). The results revealed that teens and young adults prefer social media platforms, especially visual platforms such as Instagram and the messaging application WhatsApp, as their first source of news. Another study, conducted by Arceneaux and Dinu (2018), investigated US college students' engagement on Instagram and Twitter. Using an experimental design method administered via SurveyGizmo, 405 college students were tested using textual (Twitter) and visual (Instagram) components of online information. The results showed that "the visually dominant platform of Instagram was more effective in terms of information recall than the textually dominant platform of Twitter" (Arceneaux and Dinu 2018, p. 4170). Moreover, the study concluded that the students found professional news outlets to be more credible news sources than regular social media users.

In a similar line of inquiry, Vázquez-Herrero et al. (2019) looked into Instagram Stories, with specific attention on the type of activities media outlets develop when using this new social media feature. The researchers analyzed how 60 media outlets adapted their production models to the ever-changing social media features and news consumption behaviors. They analyzed the "types, topics, resources, and purposes" of media outlets" Instagram Stories (p. 4) using a two-step quantitative analysis. First, they collected a sample from a total of 60 outlets over the week of 25-31 December 2017. Next, they performed an analysis on 17 active media platforms out of the 60 to examine the evolution of the 
use of Instagram Stories. Additionally, a questionnaire highlighting "the strategy, criteria, resources, return on investment, teamwork, and future perspectives for Instagram Stories" (p. 4) was sent to those in charge of the social media channels at the outlets being studied. The study concluded that images are the main content used in the posts, and that $44.9 \%$ of news stories were externally edited before being uploaded. The most common story types were introductory stories that present limited information $(85.6 \%)$; sports stories were the most frequently promoted on this feature, accounting for $29.9 \%$ of the total, coming in ahead of stories about society and people.

Focusing on the visual aspects of Instagram, research combining quantitative and qualitative approaches conducted by Thomson and Greenwood (2017) analyzed users' engagement with photographs pertaining to the news. Thirty participants were interviewed and asked to rank news Instagram photographs to determine the characteristics of the images that affected their engagement (Thomson and Greenwood 2017, p. 203). The study revealed that the users had varying motivations for engaging on Instagram. While most of the participants engage on Instagram for social interaction, others use Instagram as a platform for news, information and entertainment.

In terms of studies that examined Instagram news content, Greer and Ferguson (2017) investigated how news media organizations in the U.S. utilize their Instagram pages. A total of 383 Instagram pages from local TV news stations were chosen for the study which examined over 4300 Instagram posts from the period of October 2015 to January 2016. Using content analysis, the posts were coded according to whether they related to community news, "station promotion, lifestyle, behind-the-scenes content, and generic visuals unrelated to news" (Greer and Ferguson 2017, p. 289). The study concluded that for all the Instagram pages, "news and promotion were the top themes of the posts" (Greer and Ferguson 2017, p. 282). Moreover, the study found that the audiences were more engaged with posts about news and community since these stories received a higher number of likes compared to posts about lifestyle, promotion and behind-the-scenes production of news. Following a quantitative approach, a study conducted by Holiday et al. (2019) analyzed the visual framing of Instagram photos from photojournalist David Guttenfelder in North Korea. The study covered 490 of Guttenfelder's Instagram images about North Korea from 2012 to 2014. The images were coded using variables, including military, weapons, propaganda, and government figures (Holiday et al. 2019, p. 239). They found that 26\%, or 128 of the 490 images, had themes pertaining to totalitarianism. The study also revealed that news outlets that featured Guttenfelder's photos, such as National Geographic and the Denver Post, also increased the depiction of the theme of totalitarianism in their own news articles (Holiday et al. 2019, p. 240).

In another study, Borges-Rey (2015) looked at the ways in which professional and citizen photojournalists use Instagram to upload their pictures, and how their use of the platform's photo-retouching options can create a hyperreality, affecting the practice of modern journalism. Using a visual analysis model, Borges-Rey used a sample of 120 photographs, examining 10 photographs each from six professional and six citizen photojournalists. Focusing on the underlying meanings of a photograph, Borges-Rey first cataloged distinguishable visual cues along with statistics from Instagram gathered by Iconosquare. For the second step of their analysis, they grouped these visual cues into "conventional production techniques and conventional post-production techniques" (p. 579). The results showed that the use of visual effects such as color saturation and blurriness could create a new model that is different from standard realism and traditional photojournalism (p. 584).

Finally, there are several studies of Instagram audience posts about newsworthy events. Al Nashmi's (2018) research, for instance, analyzed the changes in Instagram users' postings after the Charlie Hebdo shooting in Paris which was "one of the most covered and online-trending news events of 2015" (Al Nashmi 2018, p. 98). A total of 20,148 Instagram posts were collected from January 2015, of which a random sample of 1000 images was analyzed. Using quantitative content analysis, two coders examined the posts by type, 
use of text, source, visual frames, and comment language (Al Nashmi 2018, p. 105). The coders sorted the Instagram user profiles according to gender, location, age, and level of political activity (Al Nashmi 2018, p. 105). Results of this study revealed that Instagram users posted images about the incident rather than personal photos of themselves. The study also found that while the incident happened in France, most of the posts immediately following the shooting were made from outside France and that Instagram users "shifted from a reactionary mode in the first two days to an informative and visual citizen journalist mode in the next two days" (Al Nashmi 2018, p. 98).

The above studies have sketched out important lines of inquiry, but there remains a significant gap in the literature dealing with empirical examination of Instagram news in terms of both the news organizations' practices and their audiences' engagement. In order to fill this gap in the literature, we are applying news values theory on a relatively large dataset of Instagram news, using a cross-national comparative approach.

As a social media platform, Instagram is different from Facebook, Twitter, and YouTube as there is more emphasis on aesthetic qualities of images and videos, which can potentially enhance users' engagement (Thomson and Greenwood 2017). Regarding Instagram news, there seems to be emphasis by news organizations to carefully select, package, and post the most appealing stories that have some of these aesthetic features to further encourage audience engagement through, for example, likes. This factor certainly limits the number of news items that are almost always accompanied by high quality images and/or videos. The large difference in the number of news stories posted by the same news organization can be noted by comparing Twitter and Instagram. For example, CNN's English Twitter news items are over 300,000, while its Instagram account includes about 6000 stories, and the same can be observed with BBC's English news stories that are over 400,000 on Twitter yet around 8000 on Instagram.

\section{News Values Theory}

News values theory can be partly traced back to the ideas of Walter Lippmann (1922) in his book Public Opinion that was first published in 1922, highlighting how the selection of news by journalists is based on certain factors assessed by the values or criteria they follow (p. 348). However, the operationalization of news values research started with the work of Galtung and Ruge (1965). Seen as the "foundation study of news values" (Bell 1991, p. 155), Galtung and Ruge gave the way for reshaping news values through the use of their list of news factors. The authors' research has since been viewed as an opportunity to become "a classic social science answer to the question 'what is news?'” (Tunstall 1970, p. 20).

From a professional journalistic view, Bell (1991) described news values as "the-often unconscious-criteria by which news workers make their professional judgments as they process stories" (p. 155). Shoemaker and Reese (1996) explained that news is impacted by both standard newsroom practices and the ideological values of journalists and their organizations. Journalists follow an ideology that they might not be consciously committed to (Hall 1985). However, Strömbäck et al. (2012) believe news values should include various considerations, "some of which have less to do with the news value of potential stories and more with practical, economic or format considerations. Hence, it cannot be assumed news values equals news selection" (p. 721). Caple and Bednarek (2016) shared similar views regarding the existence of a set of guidelines used by journalists to publish news (p. 436), and this is followed by practical attempts to better conceptualize news values theory (Vos and Finneman 2017).

In practical terms, Galtung and Ruge (1965) highlighted 12 main factors that can make an event newsworthy. Eight factors are based on perception (Caple 2018) which are, frequency, threshold (absolute intensity, intensity increase), unambiguity, meaningfulness (cultural proximity, relevance), consonance (predictability, demand), unexpectedness (unpredictability, scarcity), continuity, and composition. While four factors are culture-related, these are references to elite nations, elite people, personification, and negativity. Despite being looked at as valuable (Kepplinger 2008; O'neill and Harcup 2009) and as factors that 
guide the selection of news by the audience and not only journalists (Eilders 2006), the limitations of Galtung and Ruge's news values selection (1965) have been highlighted in several studies due to the changing news ecosystem.

To begin with, Caple (2018) along with Harcup and O'Neill (2001) addressed Galtung and Ruge's confined focus on events as the sole dimension to access factors that define news values (Galtung and Ruge 1965, p. 71). "Events do not possess drama" and are rather "narrated dramatically" (Vos and Finneman 2017, p. 277). Bednarek and Caple (2017) stated that being limited to events is complicated given that "(i) it treats events as monolithic; (ii) it assumes newsworthiness can easily be objectively determined and that events are either newsworthy or not; and (iii) it seemingly ignores human intervention (social cognition and discursive mediation)" (p. 31).

As Brighton and Foy (2007) explained, Galtung and Rouge lived in a different media climate with no live television or real-time news dissemination. Hoskins and $\mathrm{O}^{\prime}$ Loughlin (2007) defied the 'frequency' factor addressing television news coverage, as its connectivity and representation changed the pace in which we perceive events (Caple 2018, p. 8), while Tunstall (1971) noted the absence of the visual element of news reporting. Additionally, Brighton and Foy (2007) noted the lack of the individual perspective of the journalist, editor and publisher in Galtung and Ruge's criteria.

Despite the major criticism, it is worth examining how some of Galtung and Ruge's factors remain valid and sometimes adjusted by scholars who followed their work (Eilders 2006; Harcup and O'Neill 2001). Ostgaard (1965), for instance, connected news values with political and socioeconomic conditions, stating that the production of news is impacted by internal factors related to simplification, identification, sensationalism and news barriers as well as external factors due to political and economic reasons related to the cost of production and editorial policy (p. 44). Following Ostgaard, Denis MacShane (1979) classified newsworthy events into the following categories: conflict, hardship and danger to the community, unusualness, scandal, and individualism (p. 46). In the same year, Golding and Elliot (1979) renamed a few of Galtung and Ruge's factors and added importance, entertainment and recency, in addition to visual attractiveness, noting how film increases the chances of a story being included (p. 116). Though this was written more than 40 years ago, this remains an interesting observation especially that it ties well with our current research on news values as there are aesthetic elements that often define the type of news on Instagram.

With more interest in the cognitive aspect of news factors, Schultz (1982) focused on the connection between the form of news and audiences' awareness of events. News consumers also apply selection criteria (Ziegele et al. 2014) to deal with the flow of information and decide on relevant news (Garcia-Perdomo et al. 2018). Schultz added dimensions similar to news factors proposed by Galtung and Ruge which include status, valence, relevance, identification, consonance and dynamics.

Using events as the main point of analysis, Shoemaker et al. (1991) used social and deviance dimensions to separately predict newsworthiness. Shoemaker and Cohen (2006) assigned four elements for social significance which include economic, cultural, public, political dimensions and three elements for deviance which include statistical, social change, and normative. The authors attributed these news selection elements to evolutionary reasons since "people have been biologically influenced to attend to deviance and culturally influenced to attend to social significance" $(1991$, p. 9). Similarly to Shoemaker and Cohen's assertion (Shoemaker and Cohen 2006); Venables (2005) explored the proximity of events and their possible personal danger in relation to what determines news values.

Though proximity has been mostly looked at from a geographical angle (Badenschier and Wormer 2012) along with a cultural one (Bednarek and Caple 2014), it became a valuable factor in news values theory, following the global increase in information dissemination due to technological changes (Kern 1983). Adams (1986), for instance, studied the value of proximity given the global economic, cultural and political connections between nations, while Cohen et al. (1990) examined proximity in news values by pointing out 
the concept of psychological proximity, which can help understand how audiences and journalists decide on certain news based on relevance to their lives.

Furthermore, Bell (1991) divided news values into three groups: (1) news content, which included values like recency, unexpectedness and superlativeness, (2) the news process itself, including continuity, competition and prefabrication, and (3) the quality or style of text which includes values like clarity, brevity and color. Similar to Bell's (1991) connection of news values with mainstream ideologies held in society, Fowler (1991) conceptualized news values as culturally and socially constructed, not natural, something Hall (1973) emphasized a few decades earlier.

Considering the recent digital age transformations in the news industry and shifts in the relation between news providers and consumers, Harcup and O'Neill (2001) suggested a revised list which included bad news, surprise, entertainment, relevance, follow-up, the power elite, celebrity, good news, magnitude and news organization's agenda. The list was also updated to cover the essential news experience of sharing news on social media websites; as for the new refined elements, they included exclusivity, conflict, audio visuals, shareability and drama (Harcup and O'Neill 2016). Further, Brighton and Foy (2007) suggested other news values elements (pp. 5-6) though they still overlapped with previous studies (Caple and Bednarek 2013). Brighton and Foy's news values elements covered relevance, topicality, composition, expectation, unusualness, worth and external factors.

Another contemporary attempt to look at news values was done by Bednarek and Caple (2017), concentrating solely on the newsworthiness of events "as constructed through discourse" (p. 42). The authors, using a discursive news values analysis to understand the formation of news values from semiotic modes of text and image (Makki 2019), only considered the presentation of news by examining the linguistic and visual construction of events.

Overall, the various news values elements largely followed Galtung and Ruge's original list with some elements only different in name (Caple 2018). More recent studies produced new news values that included unexplored aspects, such as considering the nature of digital news, emotional Reactions, reviewing audiences' news choices and describing consumers' interactions with online content (Muddiman and Stroud 2017; Weber 2014). However, the different conceptualizations presented above suggest challenges in defining distinct elements that affect newsworthiness, especially if one takes into account the fact that news values are influenced by different eras and technological developments (Parks 2018). In this respect, Caple (2018) asks the following integral questions: "Are news values the values that journalists hold, the selection criteria that they apply, the perceived qualities of material events, or values that can be discovered in published news stories?" (p. 10). Thus, considering news values mainly as a list of elements is debatable (Hetherington 1985), and previous studies suggest that "who is selecting news, for whom, in what medium and by what means (and available resources)" (Harcup and O'Neill 2016, p. 1483) is as important as factors that define news values.

This study aims to examine news in an under-research social media platform in which news is packaged and disseminated differently than other social media outlets. This study attempts to answer the following research questions:

RQ1: Based on the manual assessment of Instagram news, what do audiences like the most, and what are the differences in their news engagement?

RQ2: Based on topic modeling analysis, what are the dominant topics that English and Arabic language news organizations emphasize in their overall reporting?

\section{Methodology}

In terms of data collection, we downloaded 123,683 Instagram news stories on 6 June 2019 which is the date the study began. All the news stories posted from the beginning of creating these Instagram accounts until 30 June 2019 were collected and analyzed. Using an adapted Python code, the news stories are taken from the following 12 media TV channels, in two languages, English and Arabic: CNN, BBC, France 24, SkyNews, 
Al Jazeera, and EuroNews. We believe this is a substantial collection of these posts that attempts to understand audience engagement with Instagram Stories as well as holistically examining the major topics of each news organization. Then, we narrowed our sample down by focusing on the top 50 news stories from each outlet in each language, based on which posts had the most likes (Table 1). The collected news stories which had received a total of over 265 million likes were all the news organizations had posted on Instagram. These 600 news stories which received a total of $17,788,836$ likes were qualitatively coded based on their multimodal features including textual captions and audio-visual contents. Subsequently, we deductively designed the codebook following some of the major categories of news stories listed in the empirical study of news values by Shoemaker and Cohen (2006, p. 37). From these 26 main types and numerous other sub-types of new stories, we selected seven major topics that are recurrent on Instagram news and made some modifications to the categories to fit our study. The slight changes were made based on the researchers' preliminary examination of Instagram news stories that often have some distinctive features, such as their appealing visual and video content, which are not always the case with news disseminated on websites or other social media platforms. The news stories' types we initially examined included: (1) politics (internal/regional/international), (2) internal order(violence/war/terrorism/conflict/protest), (3) sports (national/international), (4) ceremony- (commemoration, remembrance), (5) human interests (human suffering/compassion/animals/celebrities/rescue/record breaking/mystical), (6) general information (news/utility/practical value), and (7) disasters/ accidents/epidemics. We combined internal, regional, and international politics together because of the broad scope of the international media outlets we had selected, while adding a few sub-types to human-interest stories, such as rescue, human suffering and compassion to make them fit our study on Instagram news stories. Regarding category (6), the majority of general news is positive in nature, similar to the features classified under human-interest.

Table 1. Total number of news stories collected from 12 news outlets.

\begin{tabular}{ccccccc}
\hline No. & $\begin{array}{c}\text { English News } \\
\text { Outlet }\end{array}$ & Stories & $\begin{array}{c}\text { No. of } \\
\text { Likes }\end{array}$ & $\begin{array}{c}\text { Arabic News } \\
\text { Outlet }\end{array}$ & Stories & $\begin{array}{c}\text { No. of } \\
\text { Likes }\end{array}$ \\
\hline 1. & CNN & 6102 & $131,277,093$ & CNN Arabic & 1138 & 260,640 \\
\hline 2. & BBC News & 8131 & $98,405,859$ & BBC Arabic & 1844 & $1,551,769$ \\
\hline 3. & France 4 & 4951 & $1,750,050$ & France24 Arabic & 2950 & 884,666 \\
\hline 4. & SkyNews & 4165 & $3,543,943$ & SkyNewsArabia & 4183 & $4,807,954$ \\
\hline 5. & Al Jazeera & 2440 & $17,256,673$ & Al Jazeera & 7137 & $4,829,615$ \\
\hline 6. & Euronews.tv & 1309 & 614,759 & Euronews Arabic & 1237 & 94,714 \\
\hline- & Total & 67,946 & $252,848,377$ & - & 55,737 & $12,429,358$ \\
\hline
\end{tabular}

In manually coding the news stories, two coders focused their attention on the overarching or most important topic in each news story, so that the data is mutually exclusive. The two coders examined $10 \%$ of the data, which is a representative sample $(n=60)$, and the inter-coder reliability was measured using Krippendorff's alpha, or coefficient, for nominal data (Freelon 2010). Krippendorff asserts that it "is customary to require $\alpha \geq 0.800$. Where tentative conclusions are still acceptable, $\alpha \geq 0.667$ is the lowest conceivable limit" (Krippendorff 2004, p. 429). In our first coding attempt, we reached an acceptable agreement $(\alpha \geq 0.675)$. In our second coding attempt, after further coder training, deliberation and reconsideration of some of the coding decisions, we reached a higher level of agreement ( $\alpha \geq 0.853)$. In our opinion this remains a major weakness in news values as a method because many stories can contain more than one topic. For example, the topic of news about a gun violence victim commemoration could be coded in several categories $(2,4$, and 5) in our study. Unfortunately, Shoemaker and Cohen (2006) do not provide a detailed description of how their coding of topics was conducted. As an alternative, the same 
sample was coded for a third time by taking into account the different available topics without considering the overarching, or dominant, topic only. Once again, the two coders reached an overall acceptable agreement on the first attempt $(\alpha \geq 0.680)$. We then decided to focus our attention on coding the remaining dataset by identifying the main or dominant topic, since the inter-coder agreement was much higher and the third coding scheme was more time consuming. It is important to note that we did not incorporate the dimensions of deviance and significance from Shoemaker et al.'s study because the most liked stories we selected largely contained these aspects, especially significance, in varying degrees. We also did not take into account the number of Instagram video views because this measure excludes news that contains only images and/or texts. Another dimension that we left out was the number of news comments because many social media users might comment on a story to show disagreement or express dislike. The other reason why we did not focus on the most commented on news stories was the relatively low engagement which amounted to 690,678 comments in comparison to the high number of likes which was over 17 million for all the stories we examined. Finally and unlike other social media platforms, there are less metadata options available when examining news engagement on Instagram than, for instance, on Facebook that has comments, likes, shares, video views, and four emotional Reactions features.

Furthermore, likes offer an important indicator of news audience engagement on social media (Hermida et al. 2012), and many scholars take them into account when deciding on which type of content to focus on to understand how audiences engage with and react to news (Winter et al. 2015; Kim 2018; Dvir-Gvirsman 2019). As Larsson emphasizes in his study on Instagram news, "the process of interacting by means of "likes" could be seen as an example of medium interactivity" (Larsson 2018, p. 2229). This interactivity is important because news audiences take into account some metrics, such as the number of likes when deciding which news stories to pay attention to, while journalists and news organizations regularly monitor them because they offer important indicators of audience engagement.

As for the second stage of the study, we followed a digital approach by analyzing all the Instagram news stories posted by news organizations in order to understand the dominant news topics. Due to the large dataset, we employed topic modeling, which normally "generate[s] words based on latent topic variables inferred from word correlations independent of the order in which the words appear" (Wallach 2006). Many studies have used topic modeling to study news coverage of certain topics, including big data on Twitter, online comments, and various issues in journalism (Berendt 2011; Boumans and Trilling 2016; Conover et al. 2013; DiMaggio et al. 2013; Ghosh and Guha 2013; Jacobi et al. 2016; Kang et al. 2013; Kigerl 2017; Levy and Franklin 2014). For this study, we employed Factor Analysis (FA) in our topic modeling approach in order to identify the latent semantic concepts. For this purpose, we used a commercial software called QDA Miner 5-Word Stat 8 (Péladeau and Davoodi 2018). Since the 1960s, FA has been used in the categorization of topics from unstructured data sets in various disciplines including linguistics, psychology, and health (Borko and Bernick 1963; Harway and Iker 1964; Iker and Harway 1965). FA indicates the "factor loading", which refers to "the strength of the relationship of each word to each topic", while the data "dimensionality reduction in FA is based on the idea that each word is the representation of a linear combination of underlying hidden variables (i.e., topics)" (Péladeau and Davoodi 2018). Following Kaiser's criteria, we used the mathematical linear of the Eigenvalue value to rank the topics with $>1$ value rule (Kaiser 1960; Marcus and Minc 1988, p. 145); the higher the value, the more prominent the topic is in the examined document (Péladeau and Davoodi 2018).

\section{Results and Discussion}

This study deals with the empirical investigation of news values on Instagram from a sample of 12 English and Arabic news channels. There are, generally, slight differences in the total number of news stories posted on the English news outlets $(n=67,946)$ in 
comparison to the Arabic counterparts $(n=55,737)$. A greater difference, however, can be seen in the audiences' engagement levels, with English language news audience far more engaged than Arabic language audiences. On average, each English language news story received 3721 likes, whereas Arabic language stories average only about 223 likes. This is perhaps not that surprising of a finding. The fact that English is a global language, and therefore the English language content has a much larger potential audience, could help explain the stark difference.

To answer the first research question about which news topics English and Arabic language audiences like the most, our findings indicate that general news/utility/information stories which are mostly positive stories come first $(30.1 \%)$, closely followed by humaninterest stories that often include strong emotional features, such as animals or rescue operations $(27.5 \%)$. Positive news stories often involve the simple sharing of practical information or inspirations sayings, such as the case with France24's Arabic Instagram page which routinely posts famous quotes, puzzles, and wise sayings in addition to their regular news coverage. Other recurrent news types include internal order (14.3\%), politics (8.1\%), and sports $(7.8 \%)$ (Table 2$)$. Upon examining the top 20 most liked posts, which together received $24.6 \%$ of the total likes in the examined dataset $(n=4,386,172)$, we found that 12 out of these 20 stories were human-interest (Table 3). Interestingly, the English channels for $\mathrm{CNN}(\mathrm{n}=13)$ and the BBC $(\mathrm{n}=7)$ had the highest number of most liked stories, which show the popularity of these two channels among global audiences. Our findings are similar to those of previous studies that examined news values on other social media platforms, such as Twitter and Facebook, which found human-interest stories remain prominent among social media audiences (Garcia-Perdomo et al. 2018, p. 1191). This specific finding, in fact, provides an indication of the similar nature of news audiences across different social media platforms.

Table 2. News topics' frequencies along 12 English and Arabic news outlets.

\begin{tabular}{|c|c|c|c|c|c|c|c|c|c|c|c|c|c|c|}
\hline No. & Topics & $\mathrm{CNN}$ & $\underset{\mathrm{A}}{\mathrm{CNN}-}$ & BBC & $\begin{array}{c}\text { BBC- } \\
\text { A }\end{array}$ & France24 & $\begin{array}{c}\text { France24- } \\
\text { A }\end{array}$ & Aljazeera & $\begin{array}{c}\text { Aljazeera- } \\
\text { A }\end{array}$ & $\begin{array}{l}\text { Sky } \\
\text { News }\end{array}$ & $\begin{array}{c}\text { SkyNews- } \\
\text { A }\end{array}$ & Euronews & $\begin{array}{c}\text { Euronews- } \\
\text { A }\end{array}$ & $\begin{array}{c}\text { Total \& } \\
\text { Perc. }\end{array}$ \\
\hline 1. & Politics & 5 & 1 & 2 & 3 & 6 & 3 & 3 & 7 & 2 & 6 & 4 & 7 & $49(8.1 \%)$ \\
\hline 2. & $\begin{array}{c}\text { Internal } \\
\text { order }\end{array}$ & 5 & 8 & 1 & 11 & 5 & 5 & 17 & 8 & 2 & 8 & 1 & 15 & $\begin{array}{c}86 \\
(14.3 \%)\end{array}$ \\
\hline 3. & Sports & 2 & 7 & 2 & 8 & 7 & 3 & 3 & 1 & 3 & 9 & 1 & 1 & $47(7.8 \%)$ \\
\hline 4. & Ceremony & 5 & 3 & 0 & 4 & 6 & 6 & 3 & 5 & 2 & 1 & 4 & 2 & $41(6.8 \%)$ \\
\hline 5. & $\begin{array}{l}\text { Human } \\
\text { interest }\end{array}$ & 24 & 14 & 34 & 7 & 4 & 6 & 4 & 6 & 33 & 5 & 14 & 14 & $\begin{array}{c}165 \\
(27.5 \%) \\
\end{array}$ \\
\hline 6. & $\begin{array}{l}\text { General } \\
\text { news/info/ } \\
\text { utility }\end{array}$ & 9 & 12 & 8 & 15 & 16 & 27 & 18 & 23 & 7 & 15 & 22 & 9 & $\begin{array}{c}181 \\
(30.1 \%)\end{array}$ \\
\hline 7. & Disasters & 0 & 5 & 3 & 2 & 6 & 0 & 2 & 0 & 1 & 6 & 4 & 2 & $31(5.1 \%)$ \\
\hline
\end{tabular}

As for the audiences who consume English and Arabic news stories, our study shows that there are some differences between the two types of audiences (Table 4). We can see that English language news audiences prefer Instagram story topics that revolve around human-interest $(37.6 \%)$, general news $(26.6 \%)$, and internal order $(10.3 \%)$. Arabic language news audiences, conversely, like Instagram story topics that deal with general news (33.6\%), internal order $(18.3 \%)$, and human-interest (17.3\%). These percentages do not necessarily appear all that divergent, but looking at the Standard Deviation (SD) for each topic provides a better indication of the differences. For example, the largest SD between English and Arabic news channel is seen in human-interest stories (SD $=43.13)$, followed by internal order $(\mathrm{SD}=16.97)$ and general news $(\mathrm{SD}=14.84)$. The topics with the least deviation between English and Arabic news audiences are related to ceremony $(\mathrm{SD}=0.70)$, disasters $(\mathrm{SD}=0.70)$, and politics $(\mathrm{SD}=3.53)$. 
Table 3. The top 20 most liked Instagram news stories.

\begin{tabular}{|c|c|c|c|c|c|}
\hline No. & Date & Outlet & Link & Likes No. & Topic No. \\
\hline 1. & 4 December 2018 & $\mathrm{BBC}$ & https://www.instagram.com/p/Bq9-ujUlVFn & 268,982 & 5 \\
\hline 2. & 17 May 2019 & CNN & https://www.instagram.com/p/Bxj0Vp1jLO9 & 263,750 & 6 \\
\hline 3. & 11 January 2019 & $\mathrm{CNN}$ & https://www.instagram.com/p/BsfxSkSFty7 & 255,230 & 5 \\
\hline 4. & 27 March 2019 & $\mathrm{CNN}$ & https://www.instagram.com/p/BvhJ_VJDmW0 & 253,104 & 5 \\
\hline 5. & 2 April 2019 & $\mathrm{BBC}$ & https://www.instagram.com/p/Bwj7XxqnjWG & 244,445 & 5 \\
\hline 6. & 22 April 2019 & CNN & https:/ /www.instagram.com/p/BwkSRgCjh1u & 241,243 & 5 \\
\hline 7. & 15 April 2019 & $\mathrm{BBC}$ & https://www.instagram.com/p/BwSTyTVHQIz & 240,416 & 7 \\
\hline 8. & 7 June 2019 & $\mathrm{CNN}$ & https:/ / www.instagram.com/p/ByaX-NXjQga & 234,276 & 2 \\
\hline 9. & 24 April 2019 & $\mathrm{CNN}$ & https://www.instagram.com/p/Bwo5fq4jvc- & 222,241 & 2 \\
\hline 10. & 27 May 2019 & CNN & https://www.instagram.com/p/Bx9g-4rDKK- & 217,760 & 5 \\
\hline 11. & 25 April 2019 & $\mathrm{BBC}$ & https://www.instagram.com/p/BwrufMHnSLw & 215,210 & 6 \\
\hline 12. & 15 May 2019 & $\mathrm{CNN}$ & https://www.instagram.com/p/Bxf0NzZDuHh & 213,765 & 5 \\
\hline 13. & 6 February 2019 & $\mathrm{CNN}$ & https:/ /www.instagram.com/p/Btjjk2UAzMj & 209,578 & 2 \\
\hline 14. & 20 March 2019 & $\mathrm{BBC}$ & https://www.instagram.com/p/BvOoZJlHSK_ & 204,586 & 5 \\
\hline 15. & 15 May 2019 & $\mathrm{CNN}$ & https:/ / www.instagram.com/p/BxfHBQaDs6a & 192,611 & 1 \\
\hline 16. & 29 May 2019 & $\mathrm{CNN}$ & https://www.instagram.com/p/ByDCgALjuRm & 185,707 & 6 \\
\hline 17. & 4 March 2019 & $\mathrm{CNN}$ & https://www.instagram.com/p/Bul_p8pgpV4 & 185,602 & 5 \\
\hline 18. & 8 April 2019 & $\mathrm{BBC}$ & https://www.instagram.com/p/Bv_WtZiHpjj & 183,389 & 5 \\
\hline 19. & 9 January 2019 & $\mathrm{CNN}$ & https:/ / www.instagram.com/p/BsbhQntFOFP & 181,784 & 5 \\
\hline 20. & 8 May 2019 & $\mathrm{CNN}$ & https://www.instagram.com/p/BxM0C7GnVJ- & 172,493 & 5 \\
\hline
\end{tabular}

Table 4. Comparison of news topics prominence between English and Arabic news outlets.

\begin{tabular}{cccccc}
\hline No. & Topics & $\begin{array}{c}\text { English Outlets } \\
\text { Freq. \& Perc. }\end{array}$ & $\begin{array}{c}\text { Arabic Outlets } \\
\text { Freq. \& Perc. }\end{array}$ & Mean & $\begin{array}{c}\text { Std. } \\
\text { Deviation }\end{array}$ \\
\hline 1. & Politics & $22(7.3 \%)$ & $27(9 \%)$ & 24.50 & 3.53 \\
\hline 2. & Internal order & $31(10.3 \%)$ & $55(18.3 \%)$ & 43.00 & 16.97 \\
\hline 3. & Sports & $18(6 \%)$ & $29(9.6 \%)$ & 23.50 & 7.77 \\
\hline 4. & Ceremony & $20(6.6 \%)$ & $21(7 \%)$ & 20.50 & 0.70 \\
\hline 5. & Human interests & $113(37.6 \%)$ & $52(17.3 \%)$ & 82.50 & 43.13 \\
\hline 6. & General news $/$ info & $80(26.6 \%)$ & $101(33.6 \%)$ & 90.50 & 14.84 \\
\hline 7. & Disasters & $16(5.3 \%)$ & $15(5 \%)$ & 15.50 & 0.70 \\
\hline
\end{tabular}

Another interesting finding is that there are inter-lingual differences that other research has not explored. Sky News' English language audience, for example, mostly prefer humaninterest stories $(n=33)$, while the audience for the network's Arabic counterpart mostly prefer general news $(n=15)$, with human-interest stories receiving much less attention $(\mathrm{n}=5)$ among Arab audiences. Comparing $\mathrm{CNN}$ and the BCC's English and Arabic language audiences yields similar results.

To answer the second research question, regarding the dominant topics that English and Arabic news organizations emphasize, we used the topic modeling method because of the large dataset (See Tables 5 and 6). Due to the limited length of this paper, we only selected the top five topics from each network based on their Eigenvalue (total 30 topics). Our findings show that English language news channels mostly report on politics and internal order, accounting for $60 \%$ of Instagram posts studied $(n=18)$. In this category, 
political elites such as Donald Trump $(n=3)$ and the UK's Prime Ministers $(n=3)$ (both Theresa May and Boris Johnson) were prominent, along with a few other global politicians who received less attention such as Angela Merkel $(n=1)$ and Vladimir Putin $(n=1)$. The terrorist group ISIS was also the subject of ongoing attention from news organizations $(n=3)$, as were a few countries such as the UK $(n=1)$ and North Korea $(n=1)$. We can connect our findings to Galtung and Ruge's news values theory (1965), as newsworthy events are manifested here in the references to the elite and prominent countries, while the attention paid to ISIS falls into the category of references to something negative, or, bad news. Thus, we can see here that our news values theory provides a useful framework to interpret news worthiness in different contexts.

Table 5. Topic modelling of English news outlets.

\begin{tabular}{|c|c|c|c|c|c|c|c|c|c|c|c|c|}
\hline \multirow[b]{2}{*}{ No. } & \multicolumn{2}{|c|}{ CNN } & \multicolumn{2}{|c|}{ BBC } & \multicolumn{2}{|c|}{ France24 } & \multicolumn{2}{|c|}{ Aljazeera } & \multicolumn{2}{|c|}{ SkyNews } & \multicolumn{2}{|c|}{ Euronews } \\
\hline & Topic & $\begin{array}{l}\text { Eigen } \\
\text { value }\end{array}$ & Topic & $\begin{array}{l}\text { Eigen } \\
\text { value }\end{array}$ & Topic & $\begin{array}{l}\text { Eigen } \\
\text { value }\end{array}$ & Topic & $\begin{array}{l}\text { Eigen } \\
\text { value }\end{array}$ & Topic & $\begin{array}{l}\text { Eigen } \\
\text { value }\end{array}$ & Topic & Eigenvalue \\
\hline 1. & $\begin{array}{l}\text { North } \\
\text { Korea }\end{array}$ & 2.92 & $\begin{array}{l}\text { Islamic } \\
\text { State }\end{array}$ & 3.35 & $\begin{array}{l}\text { Cannes } \\
\text { Festival }\end{array}$ & 6.73 & $\begin{array}{c}\text { Rohingya } \\
\text { Refugee } \\
\text { Camp }\end{array}$ & 3.82 & $\begin{array}{l}\text { Harry \& } \\
\text { Meghan }\end{array}$ & 3.76 & Britain & 2.56 \\
\hline 2. & $\begin{array}{c}\text { Mass } \\
\text { shooting } \\
\text { victims }\end{array}$ & 2.7 & $\begin{array}{l}\text { Donald } \\
\text { Trump }\end{array}$ & 2.72 & $\begin{array}{l}\text { French } \\
\text { Presi- } \\
\text { dential } \\
\text { election }\end{array}$ & 2.85 & $\begin{array}{l}\text { Gaza } \\
\text { Strip }\end{array}$ & 3.22 & $\begin{array}{c}\text { UK } \\
\text { Prime } \\
\text { Minister }\end{array}$ & 3.46 & $\begin{array}{c}\text { UK } \\
\text { Prime } \\
\text { Minister }\end{array}$ & 2.23 \\
\hline 3. & $\begin{array}{l}\text { Donald } \\
\text { Trump }\end{array}$ & 2.6 & NASA & 2.11 & $\begin{array}{c}\text { Football } \\
\text { World } \\
\text { Cup }\end{array}$ & 2.65 & $\begin{array}{l}\text { Women } \\
\text { Make } \\
\text { Change }\end{array}$ & 2.55 & $\begin{array}{l}\text { Rohingya } \\
\text { Refugees }\end{array}$ & 2.93 & $\begin{array}{l}\text { Migrants } \\
\& \& \\
\text { Refugees }\end{array}$ & 1.98 \\
\hline 4. & $\begin{array}{c}\text { Prince } \\
\text { Harry \& } \\
\text { Duchess of } \\
\text { Cam- } \\
\text { bridge }\end{array}$ & 2.38 & $\begin{array}{c}\text { UK } \\
\text { Prime } \\
\text { Minister }\end{array}$ & 2.02 & $\begin{array}{l}\text { Mehdi } \\
\text { Chebil }\end{array}$ & 2.48 & ISIS & 2.45 & $\begin{array}{l}\text { Terror } \\
\text { Attack }\end{array}$ & 2.77 & $\begin{array}{l}\text { Angela } \\
\text { Merkel }\end{array}$ & 1.90 \\
\hline 5. & $\begin{array}{c}\text { Hurricane } \\
\text { Harvey }\end{array}$ & 2.21 & $\begin{array}{l}\text { Animals } \\
\text { Wildlife }\end{array}$ & 2.00 & $\begin{array}{l}\text { Fashion } \\
\text { week }\end{array}$ & 1.99 & $\begin{array}{l}\text { Refugee } \\
\text { Children }\end{array}$ & 2.31 & $\begin{array}{l}\text { Donald } \\
\text { Trump }\end{array}$ & 2.59 & $\begin{array}{l}\text { Vladimir } \\
\text { Putin }\end{array}$ & 1.86 \\
\hline
\end{tabular}

Table 6. Topic modelling of Arabic news outlets.

\begin{tabular}{|c|c|c|c|c|c|c|c|c|c|c|c|c|}
\hline \multirow[b]{2}{*}{ No. } & \multicolumn{2}{|c|}{ CNN-A } & \multicolumn{2}{|c|}{ BBC-A } & \multicolumn{2}{|c|}{ France24-A } & \multicolumn{2}{|c|}{ Aljazeera-A } & \multicolumn{2}{|c|}{ SkyNews-A } & \multicolumn{2}{|c|}{ Euronews-A } \\
\hline & Topic & Eigenvalue & Topic & Eigenvalue & Topic & Eigenvalue & Topic & Eigenvalue & Topic & $\begin{array}{l}\text { Eigen } \\
\text { value }\end{array}$ & Topic & Eigenvalue \\
\hline 1. & UAE & 2.09 & ISIS & 3.24 & $\begin{array}{l}\text { Cannes } \\
\text { festival }\end{array}$ & 11.47 & $\begin{array}{l}\text { Al Jazeera } \\
\text { Film } \\
\text { festival }\end{array}$ & 4.61 & $\begin{array}{l}\text { Moufaq } \\
\text { Qatt }\end{array}$ & 4.68 & $\begin{array}{l}\text { Yellow } \\
\text { vests }\end{array}$ & 2.76 \\
\hline 2. & Damascus & 1.73 & $\begin{array}{l}\text { Mohamed } \\
\text { Salah }\end{array}$ & 2.76 & $\begin{array}{l}\text { French } \\
\text { election }\end{array}$ & 6.05 & $\begin{array}{l}\text { Israeli oc- } \\
\text { cupation }\end{array}$ & 3.50 & $\begin{array}{l}\text { Donald } \\
\text { Trump }\end{array}$ & 2.42 & $\begin{array}{l}\text { Donald } \\
\text { Trump }\end{array}$ & 2.47 \\
\hline 3. & Cairo & 1.68 & $\begin{array}{l}\text { Donald } \\
\text { Trump }\end{array}$ & 2.61 & $\begin{array}{l}\text { African } \\
\text { Nations } \\
\text { Champi- } \\
\text { onship }\end{array}$ & 4.35 & $\begin{array}{l}\text { Syrian } \\
\text { regime }\end{array}$ & 2.83 & $\begin{array}{l}\text { Syrian } \\
\text { Refugee }\end{array}$ & 2.20 & EU & 2.04 \\
\hline 4. & American & 1.66 & $\begin{array}{l}\text { Mohammad } \\
\text { bin Salman }\end{array}$ & 2.18 & $\begin{array}{l}\text { Military } \\
\text { parade }\end{array}$ & 3.67 & $\begin{array}{l}\text { USA/ } \\
\text { Korea }\end{array}$ & 2.52 & Football & 2.10 & USA & 1.97 \\
\hline 5. & $\begin{array}{l}\text { Nicole } \\
\text { Nicholson }\end{array}$ & 1.44 & USA & 1.74 & $\begin{array}{c}\text { US } \\
\text { election }\end{array}$ & 3.52 & $\begin{array}{c}\text { Ramadhan } \\
\text { holy } \\
\text { month }\end{array}$ & 2.48 & NASA & 1.90 & $\begin{array}{l}\text { Rescue } \\
\text { opera- } \\
\text { tion }\end{array}$ & 1.28 \\
\hline
\end{tabular}

The second most prominent topic, at 23\% $(n=7)$ of the news posts, is human-interest, which includes stories that evoke strong feelings and compassion such as those showcasing the plight of migrants and refugee children, with a special focus on the Rohingya refugee crisis $(\mathrm{n}=4)$. Human-interest stories, additionally, include news topics dealing with celebrities such as Prince Harry and Meghan Markle $(n=2)$, as well as stories on animal wildlife $(n=1)$. Interestingly, there are some clear differences between English news channels. France 24's topics, for instance, are mostly related to general news, such as 
promoting the Cannes Film Festival ( $\lambda$ 6.73), fashion, and sports news. Al Jazeera English is the only channel that references the situation in Gaza, resulting from the Israeli-Palestinian military confrontations, a topic that has regional interest and proximity; Al Jazeera is based in the Middle East, with its headquarters in Qatar. In the case of France 24 and Al Jazeera, the major topics found in their coverage can be explained, following research on news values theory in terms of the elements of cultural, psychological and/or geographical proximity (Bednarek and Caple 2017, p. 91; Cohen et al. 1990; Shoemaker et al. 2007). There are zones of relevance that determine the main news focus of many news organizations. France 24, for instance, highlights the French presidential election, a topic that is completely missing from the other channels we examined. Indeed, all the channels have their own news agenda which is influenced by their ideological and cultural backgrounds, among other factors. Ideological considerations, according to Michael Schudson (2002), can be understood in this context as manifested in "the cultural knowledge that constitutes news judgment" (p. 261).

As for the major topics on Arabic language news channels, we find once more that politics and internal order come first with $63 \%(n=19)$ of the posts. These include references to elite political figures such as Donald Trump $(n=3)$ and the Saudi Crown Prince Mohammad bin Salman $(n=1)$. Sports is a more recurrent topic $(n=3)$ on Arabic language news channels than on English language news channels, while the topic of human-interest is largely missing on the Arabic outlets $(n=1)$. Once again, we find significant differences within these Arabic news channels. France 24, for example, has the Cannes Film Festival as its top topic ( $\lambda$ 11.47), closely followed by the French election; conversely, the prominent news topics featured on France 24 Arabic, interestingly, are very similar to those on its English language counterpart, which can be explained by the elements of proximity and ideology that help determine news coverage. Al Jazeera Arabic, similarly, was the only channel to feature news on the Israeli occupation, corresponding to the topic of Gaza on the channel's English counterpart. Similarly to France 24's focus on Cannes, the topic of the Al Jazeera Film Festival is the top focus of Al Jazeera Arabic ( $\lambda$ 4.61), which can be explained in terms of the news outlet's cultural, psychological, and geographical proximity. The news element of proximity also assists us in interpreting the prominence of certain countries and cities, such as the UAE, Syria, Cairo, and Damascus in the Arabic language coverage; these locations are not present in the English news coverage. There are also several relative blind spots in the major news topics of the Arabic language channels, including the refugee crisis $(n=1)$ which is somewhat surprising because we had expected to find more attention given to news on refugees and migrants.

Finally, the overall examination of the Eigenvalues provides further insight into the similarities and differences among the news channels. For example, the highest Eignevalues among all channels are found in France24 Arabic ( $\lambda$ 11.47) and English $(\lambda$ 6.73), both dealing with the topic of "Cannes Film Festival". These high Eigenvalues show the salience of this topic due to the channels' limited geographical proximity and national scope, and apparently used as part of national branding (Brown 2007; Pamment 2013). This also explains why the third highest Eigenvalue among all the channels is also related to France24 Arabic in its coverage of the French election ( $\lambda$ 6.05). Interestingly, Al Jazeera Arabic's top topic and the fourth highest Eigenvalue among all channels is the "Al Jazeera Film festival" ( $\lambda$ 4.61), indicating the similar functions of these channels in focusing on their respective countries' cultural and political events. Despite the fact that international news channels are expected to cater to the information needs of different audiences, we can still find a focus on the geographical proximity and national or regional scope among a few news outlets examined here due to the reason cited above. For example, the top two topics of SkyNews English are related to Prince Harry and Meghan ( $\lambda$ 3.76) as well as the UK Prime Minister ( $\lambda$ 3.46), while the majority of news topics covered by Euronews English are related to European affairs such as Britain ( $\lambda$ 2.56), UK's Prime Minster $(\lambda$ $2.23)$, migrants and refugees $(\lambda 1.98)$, and Angela Merkel $(\lambda 1.90)$. This finding aligns with 
previous research into news values theory and the limited geographical scope of some international news organizations (Aalberg et al. 2013; Maier 2020).

\section{Conclusions}

In this study, the major topics found on English and Arabic news outlets predominantly deal with hard and negative news, such as politics and internal order, which is in line with the results of previous research on news organizations' focus on crime and politics (Curran et al. 2010) including news on other social media platforms, such as Twitter and Facebook (Armstrong and Gao 2010). Furthermore, human-interest stories are less prominent, especially on Arabic news channels, which contrasts with their ranking by audiences in terms of most liked stories. The main focus of news organizations on Instagram appears to be news that is mostly negative, while the major news topics that Instagram audiences like are general news and human-interest stories, which are both primarily positive in nature. The overall examination of news stories shows that some news organizations have limited national or regional scope in their news reporting due to their focus on geographical proximity.

Our Instagram study corroborates previous research on the divergence between journalists' news choices and audiences' consumption habits (Boczkowski and Mitchelstein 2013; Wendelin et al. 2017). Our findings also demonstrate clear differences between English and Arabic news audiences, even on inter-lingual channels, such as the BBC, CNN, and SkyNews' English and Arabic outlets. We believe that these differences can best be interpreted and explained by contextualizing each case study. Arab audiences, for example, mostly differ from their English counterparts in their focus on internal order; this distinction can be attributed, at least in part, to the ongoing security challenges facing the Middle East. After all, audiences partly seek out and consume news for purposes related to surveillance, survival, and ultimately protection (Shoemaker and Cohen 2006). News values theory provides a convenient theoretical framework and method to examine news topics and newsworthy elements, yet there are many areas that it does not cover, such incorporating the dimensions of social significance and/or deviance with audience engagement metrics which is what we partly attempted to do in this study. This aspect requires far more attention by journalism scholars, and at times it is similar to the general approach followed by Niederer (2019) in her networked content analysis method of Twitter data.

However, this study was limited in several aspects. First, the Python script we used collected all the news stories, but missed a few; it is not clear whether or not these few missing stories were deleted, while future studies can rely on other data collection tools such as CrowdTangle. Second, to apply news values theory to our study, we selected seven main types of stories relevant to Instagram news, and thus more topics and sub-topics could be incorporated depending on the social media platform examined. We also focused our attention only on the 600 most engaging news stories, and more stories can be included in future studies.

In terms of mapping out and planning future research using the news values theory and method, we suggest adding the emotional qualities as part of the criteria used to assess the newsworthiness of an Instagram post, for example (BBC News 2019). These elements could be linked to a post's news significance by focusing on the production quality and affective or emotional triggers instead of solely relying on conscious cognitive choices (Al-Rawi 2019). Furthermore, a need exists to investigate the social media news consumption routines and preferences of broader international audiences, given that the study showed clear differences between English and Arabic audiences. Finally, inter-lingual news channels, in terms of both their news values and their audiences, remain significantly under-researched. We hope this study represents the first of many efforts to add to news media scholarship on news values and social media news.

Author Contributions: Conceptualization, A.A.-R.; Formal analysis, A.F.; Writing-review \& editing, A.A.-M. All authors have read and agreed to the published version of the manuscript. 
Funding: This research received no external funding.

Institutional Review Board Statement: Not applicable.

Informed Consent Statement: Not applicable.

Data Availability Statement: All the datasets are available with the corresponding author.

Conflicts of Interest: The authors declare no conflict of interest.

\section{References}

Aalberg, Toril, Stylianos Papathanassopoulos, Stuart Soroka, James Curran, Kaori Hayashi, Shanto Iyengar, Paul K. Jones, Gianpietro Mazzoleni, Hernando Rojas, David Rowe, and et al. 2013. International TV news, foreign affairs interest and public knowledge: A comparative study of foreign news coverage and public opinion in 11 countries. Journalism Studies 14: 387-406. [CrossRef]

Adams, William C. 1986. Whose lives count? TV coverage of natural disasters. Journal of Communication 36: 113-22. [CrossRef]

Al Nashmi, Eisa. 2018. From Selfies to Media Events. Digital Journalism 6: 98-117. [CrossRef]

Al-Rawi, Ahmed. 2019. Networked Emotional News on Social Media. Journalism Practice 14: 1125-41. [CrossRef]

Alshaer, Atef, and Andrew Hill. 2010. BBC Arabic TV: Participation and the question of public diplomacy. Middle East Journal of Culture and Communication 3: 152-70. [CrossRef]

Arceneaux, Phillip, and Lucian F. Dinu. 2018. The social mediated age of information: Twitter and Instagram as tools for information dissemination in higher education. New Media \& Society 20: 4155-76.

Armstrong, Cory L., and Fangfang Gao. 2010. Now Tweet This: How News Organizations Use Twitter. Electronic News 4: $218-35$. [CrossRef]

Badenschier, Franziska, and Holger Wormer. 2012. Issue selection in science journalism: Towards a special theory of news values for science news? In The Sciences' Media Connection-Public Communication and Its Repercussions. Dordrecht: Springer, pp. 59-85.

BBC News. 2019. Flying Red Squirrel Alert! Available online: https:/ / www.instagram.com/p/BvcVGYunk8a (accessed on 17 February 2020).

Bednarek, Monika, and Helen Caple. 2014. Why do news values matter? Towards a new methodological framework for analysing news discourse in Critical Discourse Analysis and beyond. Discourse E Society 25: 135-58. [CrossRef]

Bednarek, Monika, and Helen Caple. 2017. The Discourse of News Values: How News Organizations Create Newsworthiness. New York: Oxford University Press.

Bell, Allan. 1991. The Language of News Media. Oxford: Blackwell Publishing.

Berendt, Bettina. 2011. Text mining for news and blogs analysis. In Encyclopedia of Machine Learning. Boston: Springer, pp. 968-72.

Boczkowski, Pablo J., and Eugenia Mitchelstein. 2013. The News Gap: When the Information Preferences of the Media and the Public Diverge. Boston: MIT Press.

Borges-Rey, Eddy. 2015. News Images on Instagram. Digital Journalism 3: 571-93. [CrossRef]

Borko, Harold, and Myrna Bernick. 1963. Automatic document classification. Journal of the ACM (JACM) 10: 151-62. [CrossRef]

Boumans, Jelle W., and Damian Trilling. 2016. Taking stock of the toolkit: An overview of relevant automated content analysis approaches and techniques for digital journalism scholars. Digital Journalism 4: 8-23. [CrossRef]

Brighton, Paul, and Dennis Foy. 2007. News Values. London: SAGE.

Brown, Johan. 2007. Public diplomacy as a global phenomenon, 2006: An internet-based overview of English-language world media reports on public diplomacy-Part III: Europe and the Americas (excluding the United States). Place Branding and Public Diplomacy 3: 337-47. [CrossRef]

Caple, Helen. 2018. News Values and Newsworthiness. Oxford: Oxford Research Encyclopedia of Communication. [CrossRef]

Caple, Helen, and Monika Bednarek. 2013. Delving into the Discourse: Approaches to News Values in Journalism Studies and Beyond. Working Paper. Oxford: The Reuters Institute for the Study of Journalism, The University of Oxford.

Caple, Helen, and Monika Bednarek. 2016. Rethinking news values: What a discursive approach can tell us about the construction of news discourse and news photography. Journalism 17: 435-55. [CrossRef]

Cohen, Akiba A., Hanna Adoni, Charles R. Bantz, Deanna C. Robinson, Jay G. Blumler, and Michael Gurevitch. 1990. Social Conflict and Television News. Newbury Park: Sage Publications, Inc.

Conover, Michael D., Emilio Ferrara, Filippo Menczer, and Alessandro Flammini. 2013. The digital evolution of occupy wall street. PLoS ONE 8: e64679. [CrossRef]

Curran, James, Inka Salovaara-Moring, Sharon Coen, and Shanto Iyengar. 2010. Crime, foreigners and hard news: A cross-national comparison of reporting and public perception. Journalism 11: 3-19. [CrossRef]

DiMaggio, Paul, Manish Nag, and David Blei. 2013. Exploiting affinities between topic modeling and the sociological perspective on culture: Application to newspaper coverage of US government arts funding. Poetics 41: 570-606. [CrossRef]

Dvir-Gvirsman, Shira. 2019. I like what I see: Studying the influence of popularity cues on attention allocation and news selection. Information, Communication E Society 22: 286-305.

Eilders, Christiane. 2006. News Factors and News Decisions. Theoretical and Methodological Advances in Germany. Communications 31: 5-24. [CrossRef]

Fowler, Roger. 1991. Language in the News: Discourse and Ideology in the Press. London: Routledge. 
Freelon, Deen G. 2010. ReCal: Intercoder reliability calculation as a web service. International Journal of Internet Science 5: 20-33.

Galtung, Johan, and Mari Holmboe Ruge. 1965. The structure of foreign news: The presentation of the Congo, Cuba and Cyprus Crises in four Norwegian newspapers. Journal of Peace Research 2: 64-90. [CrossRef]

Garcia-Perdomo, Victor, Ramon Salaverria, Danielle K. Kilgo, and Summer Harlow. 2018. To share or not to share: The influence of news values and topics on popular social media content in the United States, Brazil, and Argentina. Journalism Studies 19: 1180-201. [CrossRef]

Ghosh, Debarchana, and Rajarshi Guha. 2013. What are we 'tweeting' about obesity? Mapping tweets with topic modeling and Geographic Information System. Cartography and Geographic Information Science 40: 90-102. [CrossRef]

Golding, Peter, and Philip Ross Courtney Elliot. 1979. Making the News. London: Longman.

Greer, Clark, and Douglas A. Ferguson. 2017. The local TV station as an organizational self: Promoting corporate image via Instagram. International Journal on Media Management 19: 282-97. [CrossRef]

Hall, Stewart. 1973. The Determination of News Photographs. In The Manufacture of News: A Reader. Edited by Cohen Stanley and Jack Young. Beverly Hills: Sage Beverly Hills.

Hall, Stewart. 1985. Signification, representation, ideology: Althusser and the post-structuralist debates. Critical Studies in Mass Communication 2: 91-114. [CrossRef]

Harcup, Tony, and Deirdre O'Neill. 2001. What is News? Galtung and Ruge Revisited. Journalism Studies 2: 261-80. [CrossRef]

Harcup, Tony, and Deirdre O'Neill. 2016. What is News? Journalism Studies 18: 1470-88. [CrossRef]

Harway, Norman I., and Howard P. Iker. 1964. Computer analysis of content in psychotherapy. Psychological Reports 14: 720-22. [CrossRef]

Hermida, Alfred, Fred Fletcher, Darryl Korell, and Donna Logan. 2012. Share, like, recommend: Decoding the social media news consumer. Journalism Studies 13: 815-24. [CrossRef]

Hetherington, Alastair. 1985. News, Newspapers and Television. London: Macmillan Press.

Holiday, Steven, Harper D. Anderson, Matthew J. Lewis, and Rachel C. Nielsen. 2019. You are what you are in this world: Visual framing and exemplification in media coverage of the Guttenfelder Instagram photographs from North Korea. Visual Communication 18: 231-50. [CrossRef]

Hoskins, Andrew, and Ben O'Loughlin. 2007. Television and Terror: Conflicting Times and the Crisis of News Discourse. Basingstoke: Palgrave Macmillan.

Iker, Howard P., and Norman I. Harway. 1965. A computer approach towards the analysis of content. Behavioral Science 10: 173-82. [CrossRef]

Jacobi, Carina, Wouter Van Atteveldt, and Kasper Welbers. 2016. Quantitative analysis of large amounts of journalistic texts using topic modelling. Digital Journalism 4: 89-106. [CrossRef]

Kaiser, Henry F. 1960. The application of electronic computers to factor analysis. Educational and Psychological Measurement 20: 141-51. [CrossRef]

Kang, Beomil, Min Song, and Whasun Jho. 2013. A study on opinion mining of newspaper texts based on topic modeling. Journal of the Korean Society for Library and Information Science 47: 315-34. [CrossRef]

Kepplinger, Hans Mathias. 2008. News values. International Encyclopedia of Communication. Available online: http://www. communicationencyclopedia.com/subscriber/tocnode.html?id=g9781405131995_yr21 (accessed on 7 February 2020).

Kern, Stephen. 1983. The Culture of Time and Space 1880-1918. Cambridge: Harvard University Press.

Kigerl, Alex. 2017. Profiling Cybercriminals: Topic Model Clustering of Carding Forum Member Comment Histories. Social Science Computer Review 36: 591-609. [CrossRef]

Kim, Ji Won. 2018. They liked and shared: Effects of social media virality metrics on perceptions of message influence and behavioral intentions. Computers in Human Behavior 84: 153-61. [CrossRef]

Krippendorff, Klaus. 2004. Reliability in content analysis. Human Communication Research 30: 411-33. [CrossRef]

Lahlali, El Mustapha. 2011. Contemporary Arab Broadcast Media. Edinburgh: Edinburgh University Press.

Larsson, Andres Olof. 2018. The news user on social media: A comparative study of interacting with media organizations on Facebook and Instagram. Journalism Studies 19: 2225-42. [CrossRef]

Levy, Karen EC, and Michael Franklin. 2014. Driving regulation: Using topic models to examine political contention in the US trucking industry. Social Science Computer Review 32: 182-94. [CrossRef]

Lippmann, Walter. 1922. Public Opinion. New York: Macmillan.

MacShane, Denis. 1979. Using the Media. London: Pluto Press.

Maier, Scott R. 2020. The world view (ed) through the English-speaking media lens: Foreign news coverage steadfastly narrow and uniform. The Journal of International Communication 26: 155-70. [CrossRef]

Makki, Mohammad. 2019. 'Discursive news values analysis' of Iranian crime news reports: Perspectives from the culture. Discourse $\mathcal{E}$ Communication 13: 437-60. [CrossRef]

Marcus, Marvin, and Henryk Minc. 1988. Introduction to Linear Algebra. New York: Dover.

Muddiman, Ashley, and Natalie Jomini Stroud. 2017. News values, cognitive biases, and partisan incivility in comment sections. Journal of Communication 67: 586-609. [CrossRef]

Nee, Rebecca C. 2019. Youthquakes in a Post-Truth Era: Exploring Social Media News Use and Information Verification Actions among Global Teens and Young Adults. Journalism \& Mass Communication Educator 74: 171-84. 
Niederer, Sabine. 2019. Networked Content Analysis: The Case of Climate Change. Amsterdam: Institute of Network Cultures.

O'neill, Deirdre, and Tony Harcup. 2009. News values and selectivity. In The Handbook of Journalism Studies. New York: Routledge, pp. 181-94.

Ostgaard, Einar. 1965. Factors influencing the flow of news. Journal of Peace Research 2: 39-63. [CrossRef]

Pamment, James. 2013. West European Public Diplomacy. In European Public Diplomacy. Edited by K. Mai'a and Jan Melissen. New York: Palgrave Macmillan, pp. 13-38.

Parks, Perry. 2018. Naturalizing negativity: How journalism textbooks justify crime, conflict, and 'bad' news. Critical Studies in Media Communication 36: 75-91. [CrossRef]

Péladeau, Normand, and Elnaz Davoodi. 2018. Comparison of Latent Dirichlet Modeling and Factor Analysis for Topic Extraction: A Lesson of History. Paper Presented at the Conference Proceedings, The Hawaii International Conference on System Sciences (HICSS), Koloa, HI, USA, 2-6 January; pp. 1-9.

Schudson, Michael. 2002. The News Media as Political Institutions. Annual Review of Political Science 5: 249-69. [CrossRef]

Schultz, Winfried Friedrich. 1982. News structure and people's awareness of political events. International Communication Gazette 30: 139-53. [CrossRef]

Shoemaker, Pamela J, and Akiba A. Cohen. 2006. News Around the World: Content, Practitioners, and the Public. London: Routledge.

Shoemaker, Pamela J., and Stephen D. Reese. 1996. Mediating the Message. New York: Longman.

Shoemaker, Pamela J., Lucig H. Danielian, and Nancy Brendlinger. 1991. Deviant acts, risky business and U.S. interests: The newsworthiness of world events. Journalism Quarterly 68: 781-95. [CrossRef]

Shoemaker, Pamela J., Jong H Lee, Gang Han, and Akiba A. Cohen. 2007. Proximity and scope as news values. In Media Studies: Key Issues and Debates. Edited by Eoin Devereux. Thousand Oaks: Sage, pp. 231-48.

Strömbäck, Jesper, Michael Karlsson, and David Nicolas Hopmann. 2012. Determinants of news content: Comparing journalists' perceptions of the normative and actual impact of different event properties when deciding what's news. Journalism Studies 13: 718-28. [CrossRef]

Thomson, T. J., and Keith Greenwood. 2017. I "Like” That: Exploring the Characteristics That Promote Social Media Engagement with News Photographs. Visual Communication Quarterly 24: 203-18. [CrossRef]

Tunstall, Jeremy, ed. 1970. Media Sociology: A Reader. London: Constable.

Tunstall, Jeremy. 1971. Journalists at Work: Specialist Correspondents: Their News Organizations, News Sources, and Competitor-Colleagues. London: Constable.

Van Cauwenberge, Anna, and Marcel Broersma. 2017. Understanding the Mobilizing Role of Social Media News Use for Political Participation: How Different Social Media Technologies Affect Online Political Conversation. Conference Papers, International Communication Association. pp. 1-33. Available online: https:/ / search-ebscohost-com.proxy.lib.sfu.ca/login.aspx?direct=true\& $\mathrm{db}=\mathrm{ufh} \& \mathrm{AN}=135750034 \&$ site=ehost-live (accessed on 9 February 2020).

Vázquez-Herrero, Jorge, Sabel Direito-Rebollal, and Xose López-García. 2019. Ephemeral Journalism: News Distribution through Instagram Stories. Social Media + Society 5: 1-13. [CrossRef]

Venables, John. 2005. Making Headlines. Huntingdon: Elm.

Vos, Tim, and Teri Finneman. 2017. The early historical construction of journalism's gatekeeping role. Journalism 18: 265-80. [CrossRef]

Wallach, Hanna M. 2006. Topic modeling: Beyond bag-of-words. In Proceedings of the 23rd International Conference on Machine Learning. New York: ACM, pp. 977-84.

Weber, Patrick. 2014. Discussions in the comments section: Factors influencing participation and interactivity in online newspapers' reader comments. New Media \& Society 16: 941-57. [CrossRef]

Wendelin, Manuel, Ines Engelmann, and Julia Neubarth. 2017. User rankings and journalistic news selection: Comparing news values and topics. Journalism Studies 18: 135-53. [CrossRef]

Winter, Stephan, Caroline Brückner, and Nicole C Kramer. 2015. They came, they liked, they commented: Social influence on Facebook news channels. Cyberpsychology, Behavior, and Social Networking 18: 431-36. [CrossRef]

Ziegele, Marc, Timo Breiner, and Oliver Quiring. 2014. What creates interactivity in online news discussions? An exploratory analysis of discussion factors in user comments on news items. Journal of Communication 64: 1111-38. [CrossRef] 